\title{
Biological evaluation and spectral characterization of novel tetracenomycin $X$ congener
}

\author{
Vera A. Alferova ${ }^{\mathrm{a}, \mathrm{b}}, \quad$ Tinashe P. Maviza ${ }^{\mathrm{c}}, \quad$ Mikhail V. Biryukov $^{\mathrm{a}, \mathrm{d}, \mathrm{e}}$,
} Yuliya V. Zakalyukina e,f, Dmitrii A. Lukianov ${ }^{\mathrm{e}}$, Dmitry A. Skvortsov ${ }^{\mathrm{g}}$, Lilia A. Vasilyeva ${ }^{\mathrm{g}}$, Vadim N. Tashlitsky ${ }^{\mathrm{g}}$ ， Vladimir I. Polshakov ${ }^{\mathrm{h}}, \quad$ Olga A. Dontsova ${ }^{\mathrm{b}, \mathrm{c}, \mathrm{g}}, \quad$ Petr V. Sergiev ${ }^{\mathrm{c}, \mathrm{g}}$, Vladimir A. Korshun ${ }^{\mathrm{a}, \mathrm{b}}$ and Ilya A. Osterman ${ }^{\mathrm{c}, \mathrm{e}, \mathrm{g} *}$

${ }^{\text {a }}$ Gause Institute of New Antibiotics, Bolshaya Pirogovskaya 11, Moscow 119021, Russia
b Shemyakin-Ovchinnikov Institute of Bioorganic Chemistry, Miklukho-Maklaya 16/10, Moscow 117997, Russia

${ }^{c}$ Center of Life Sciences, Skolkovo Institute of Science and Technology, Skolkovo, 143028 Russia

${ }^{\mathrm{d}}$ Department of Biology, Lomonosov Moscow State University, Moscow, 119234 Russia

${ }^{\mathrm{e}}$ Genetics and Life Sciences Research Center, Sirius University of Science and Technology, Sochi, 354340 Russia

${ }^{\mathrm{f}}$ Department of Soil Science, Lomonosov Moscow State University, Moscow, 119234 Russia

g Department of Chemistry, Lomonosov Moscow State University, Moscow 119992, Russia

${ }^{\mathrm{h}}$ Center for Magnetic Tomography and Spectroscopy, Faculty of Fundamental Medicine, Lomonosov Moscow State University, Moscow 119991, Russia

Corresponding Author: Ilya A. Osterman, i.osterman@skoltech.ru 


\begin{abstract}
The aromatic polyketide tetracenomycin $\mathrm{X}(\mathrm{Tcm} X)$ was recently found to be a potent inhibitor of protein synthesis, whose binding site is located in a unique locus within the tunnel of the large ribosomal subunit. The distinct mode of action makes this relatively narrow class of macrolides promising for drug development, in our quest to prevent the spread of drug resistant pathogens. Here we report the isolation and structure elucidation of novel natural tetracenomycin $\mathrm{X}$ congener - 6-hydroxytetraceonomycin $\mathrm{X}$ (6-OH-TcmX). In contrast to TcmX, 6-OH-TcmX exhibited lower antimicrobial and cytotoxic activity, but comparable in vitro protein synthesis inhibition ability. A survey on spectral properties of tetracenomycins showed profound differences in both UV-absorption and fluorescence spectra of TcmX and 6-OH-TcmX, suggesting the significant influence of 6-hydroxylation on tetracenomycin chromophore. Nonetheless, characteristic spectral properties of tetracenomycins make them suitable candidates as a foundation for semi-synthetic drug development (e.g., for targeted delivery, theranostics or cell imaging).
\end{abstract}

\title{
Keywords
}

Tetracenomycins, polyketide antibiotics, structure-activity relationship, fluorescence, spectral characteristics 


\section{Highlights}

- Hydroxylated tetracenomycin X is produced by Amycolatopsis strain

- 6-Hydroxylation reduces both tetracenomycin $X$ antimicrobial and cytotoxic activity

- 6-Hydroxylation significantly alters tetracenomycin X chromophore

- UV-Vis spectra of tetracenomycins are dependent on solvent and $\mathrm{pH}$

- Activity is impaired not due to the lower protein synthesis inhibition ability

\section{Graphical abstract}

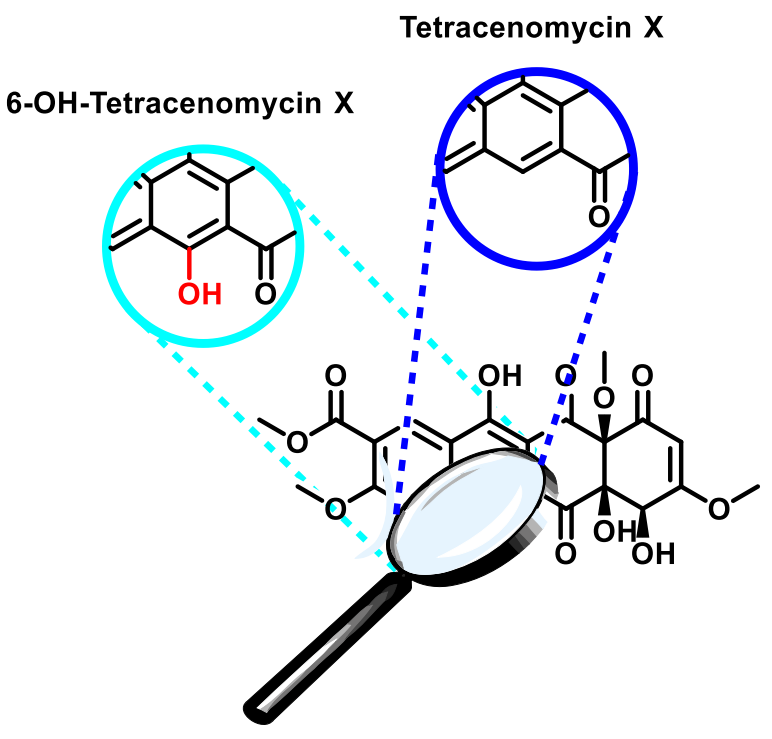




\section{Introduction}

The biosynthesis of aromatic polyketides is usually accomplished by the type II polyketide synthases (PKSs), which produce highly diverse polyketide chains by sequential condensation of the starter units with extender units, followed by reduction, cyclization, aromatization and tailoring reactions to yield a more or less planar aromatic core that contain several annulated rings [1-6]. For instance, decaketides can undergo initial 7,12-cyclization followed by anthracycline, tetracycline, or angucyline folding, and the initial 9,14-cyclization affords tetracenomycin or discoid folding [3]. More examples of compounds that contain four fused rings are given on Figure 1. The bizarre realm of four-ring aromatic polyketide antibiotics is their ability to exhibit completely different modes of biological activity, even though they are structurally similar.

Anthracyclines (doxorubicin) and tetracyclines bare significant structural similarities (Figure 1), but have completely different targets. Anthracyclines are anticancer antibiotics inhibiting function of topoisomerase II [7], whereas tetracyclines are used as antibacterials due to their ability to inhibit protein synthesis [8]. Other four ring polyketides with considerable degree of aromaticity are various angucyclines [9,10] (e.g. the parent tetrangulol, landomycins, urdamycins), as well as tetracenomycins and elloramycins. Tetracenomycins $\mathrm{C}$ and $\mathrm{X}$ have distinctive 4a,12a-diooxygenation dramatically disrupting the planar structure. 

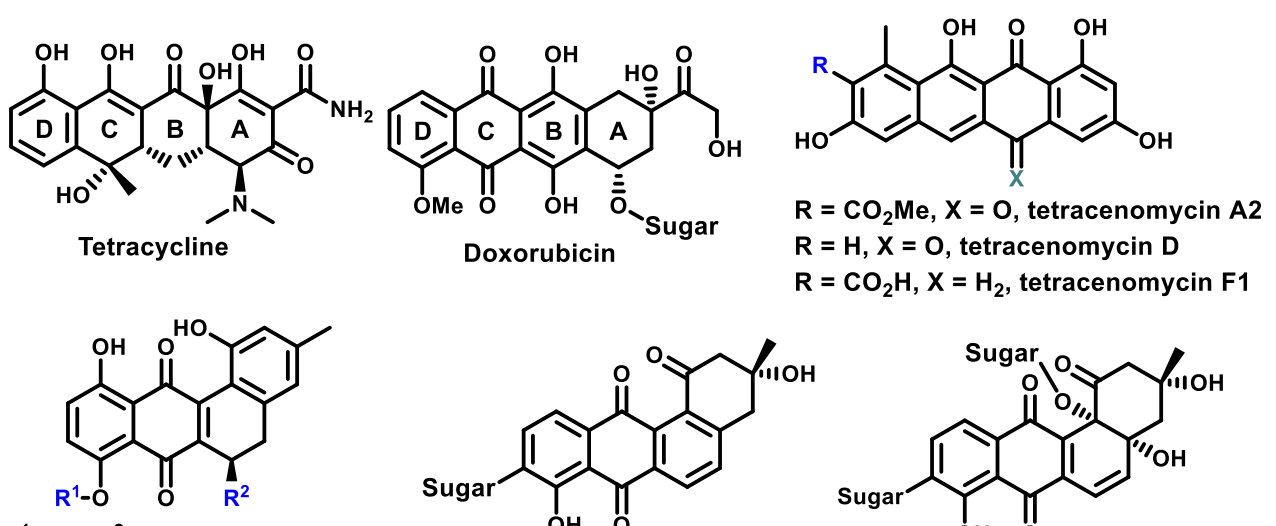

$R^{1}=H, R^{2}=H$, tetrangulol

$R^{1}=$ sugar, $R^{2}=O H$, landomycins
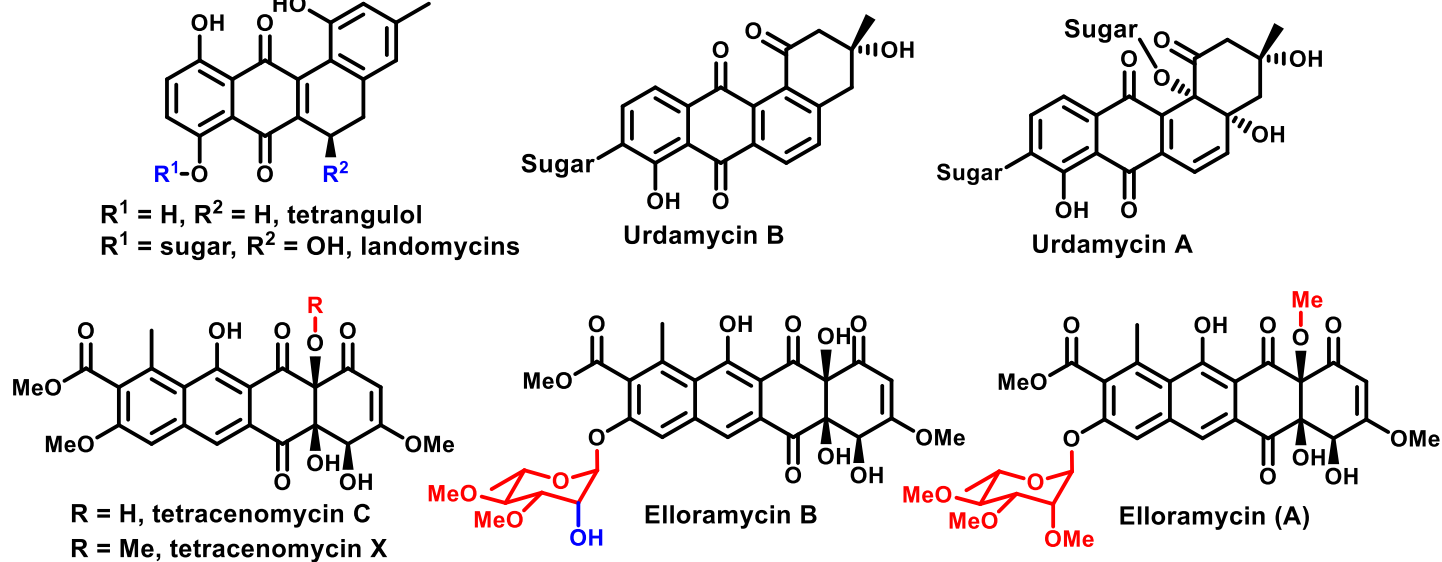

Figure 1. Examples of four-ring aromatic polyketides from several structural families.

Recently we reported a novel mechanism of action for a member of a rather understudied family of aromatic polyketides - tetracenomycin X (TcmX) [11]. Unique binding site in the large ribosomal subunit makes these compounds very attractive for further drug development. Here we report the isolation and structure elucidation of the novel member of the structural family - 6hydroxylated-tetracenomycin $\mathrm{X}(6-\mathrm{OH}-\mathrm{TcmX})$ - and its biological evaluation. We performed physicochemical characterization of the natural tetracenomycins for their further introduction into drug conjugates.

\section{Experimental}

\subsection{Cultivation Amycolatopsis sp. A23, extraction and fractionation}

The Amycolatopsis sp. A23 strain was grown as described previously [11]: in $50 \mathrm{~mL}$ of Org 79 medium for 2 days at $28^{\circ} \mathrm{C}$, and $5 \mathrm{~mL}$ of the preculture was used to inoculate seven flasks containing $150 \mathrm{~mL}$ of $\operatorname{Org} 79$ medium [12]. The cultures were then incubated at $28{ }^{\circ} \mathrm{C}$ for 21 days without shaking. Then $5 \mathrm{~L}$ was used for gravity-force reverse-phase chromatography on LPS500H sorbent (polyvinylbenzene, pore size 50-1,000 E) with elution by $10,25,50$ and $75 \%$ acetonitrile solutions. The fraction eluted by 25 and $50 \%$ of acetonitrile were evaporated and subjected to 
further purification by means of preparative high-performance liquid chromatography (HPLC) (Interchim Puriflash 4250, isocratic elution with $20 \mathrm{~mL} / \mathrm{min} 42 \%$ of $\mathrm{MeCN}, 0.1 \%$ TFA) using an Agilent ZORBAX SB-C18 $(\mathrm{C} 18 ; 250 \times 21.2 \mathrm{~mm}, 7 \mu \mathrm{m})$ column. The collected fractions were lyophilized. Fractions were analyzed with analytical HPLC (Knauer HPLC system equipped with K-2501 detector, isocratic elution with $1 \mathrm{~mL} / \mathrm{min} 42 \%$ of $\mathrm{MeCN}, 0.1 \%$ TFA) using a Sunfire column $(\mathrm{C} 18 ; 4.6 \times 250 \mathrm{~mm}, 5 \mu \mathrm{m})$. As a result, $35 \mathrm{mg}$ of $\mathrm{TcmX}$ and $2.5 \mathrm{mg}$ of $6-\mathrm{OH}-\mathrm{TcmX}$ were obtained. The chemical structure of the minor compound was revealed by combination of mass spectrometry and NMR analysis.

\subsection{NMR spectroscopy}

NMR spectra were recorded on a Bruker AVANCE spectrometer operating at a proton frequency of $600 \mathrm{MHz}$, at $298 \mathrm{~K}$ in $\mathrm{CDCl}_{3}$ with TMS as an internal reference. Assignment of ${ }^{1} \mathrm{H}$ and ${ }^{13} \mathrm{C}$ signals was obtained using the $1 \mathrm{D}{ }^{1} \mathrm{H}$ and ${ }^{13} \mathrm{C}$ spectra and $2 \mathrm{D}{ }^{1} \mathrm{H}-{ }^{1} \mathrm{H}$ ROESY (320 ms mixing time), ${ }^{13} \mathrm{C}-{ }^{1} \mathrm{H}$ HSQC and ${ }^{13} \mathrm{C}-{ }^{1} \mathrm{H}$ HMBC experiments. The ${ }^{1} \mathrm{H}$ chemical shifts were measured from TMS as an internal reference, and ${ }^{13} \mathrm{C}$ chemical shifts were referenced indirectly using $\gamma$ ratios method [13]. Spectra were processed by NMRPipe [14] using standard protocol that includes the Lorentz-to-Gauss window function, forward-backward linear prediction and polynomial baseline correction. 2D spectra were analyzed with NMRFAM-Sparky [15]. 1D NMR spectra were processed and analysed using Mnova software (Mestrelab Research, Spain).

\subsection{Quantum mechanical calculations}

Geometry of TcmX16 was optimized by Density Functional Theory (DFT) quantum mechanical calculations using the Gaussian 09w suite [16] (Figure 3B). Calculations were performed by DFT using the B3LYP functional and $6-311++\mathrm{G}(2 \mathrm{~d}, 2 \mathrm{p})$ basis set and the Polarizable Continuum Model (PCM) of chloroform solvent. ${ }^{1} \mathrm{H}$ and ${ }^{13} \mathrm{C}$ chemical shifts were calculated for each optimized model using the GIAO (Gauge Independent Atomic Orbitals) method, the mPW1PW91 functional [17], the 6-311+G(2d,p) basis set and the Polarizable Continuum Model 
(PCM) of chloroform solvent. ${ }^{1} \mathrm{H}$ and ${ }^{13} \mathrm{C}$ chemical shifts were computed from the isotropic values of SCF GIAO magnetic shielding tensors using linear regression [18] (Table S1).

\subsection{Spectral characterization}

UV-Vis absorption spectra were recorded using a Varian Cary 100 UV-Vis spectrophotometer. The fluorescence studies were carried out on a Perkin-Elmer LS 55 luminescence spectrometer. $\mathrm{pH}$ values of the solutions were adjusted by $\mathrm{HCl}$ and $\mathrm{NaOH}$. UV spectra were recorded for two concentrations of the compounds $10^{-4} \mathrm{M}$ and $2 \times 10^{-5} \mathrm{M}$, values of optical density in range $0.1-0.9$ were used for extinction coefficient calculations. The fluorescence studies were carried out on a Perkin-Elmer LS 55 luminescence spectrometer. The solvents used in this work were of the highest grade available.

\subsection{Mass-spectrometry}

Mass spectrums were made by means of ultra-efficient liquid chromatography / MS on a Waters Acquity ${ }^{\mathrm{TM}}$ UPLC-MS/MS ultraperformance LC system (Waters) supplied with TQD (ESI, MS1 mode) and PDA detectors, using an analytical column Acquity UPLC BEH ${ }^{\mathrm{TM}}$ C18 $(50 \times 2.1$ $\mathrm{mm}, 1.7 \mu \mathrm{m})$ by gradient elution $5 \%-100 \% \mathrm{MeCN}(3 \mathrm{~min})$ in the presence $20 \mathrm{mM}$ formic acid $\left(35^{\circ} \mathrm{C}, 0.5 \mathrm{~mL} / \mathrm{min}\right.$, inj. vol. $\left.2 \mu \mathrm{L}\right)$. Molecular weight of the new compound was determined as $506 \mathrm{Da}$, in the same conditions molecular weight of tetracenomycin X was detected as $486 \mathrm{Da}$.

\subsection{Biological activity testing}

\subsubsection{MIC determination}

An overnight culture of E. coli $\Delta$ tolC strain was diluted 1:1000 in LB medium. A sterile 96well plate was then loaded with $200 \mu \mathrm{L}$ of the diluted cultural media, with the initial row prior serial dilution, having $400 \mu \mathrm{L}$. Stock solutions for TcmX and 6-OH-TcmX were seeded in the initial row, along with erythromycin (Ery), which was used as a control for the experiment. Other wells were left without antibiotic, but with the diluted LB-culture media, while the remainder were left with LB media only as additional controls. A two-fold serial dilution was then executed, with gentle mixing in each row. The plate(s) where then incubated at $37{ }^{\circ} \mathrm{C}$ with shaking at $200 \mathrm{rpm}$ 
overnight. Cell growth was them measured at $590 \mathrm{~nm}$ using a microplate reader (VICTOR X5 Light Plate Reader, PerkinElmer, USA). The procedure was repeated for different sample preparations of TcmX and 6-OH-TcmX batches.

\subsubsection{In vitro translation assay}

The PURExpress system In vitro Protein Synthesis kit (NEB) was used to perform in vitro translation reactions for TcmX and 6-OH-TcmX. The reaction master-mix per reaction $(5 \mu \mathrm{L})$ included: solution A $(2 \mu \mathrm{L})$; solution B $(1 \mu \mathrm{L})$; D-luciferin $(0.1 \mu \mathrm{L})$; Ribolock $(0.1 \mu \mathrm{L})$ and MilliQ water $(1 \mu \mathrm{L})$. A volume of $4 \mu 1$ was then aliquoted in to the sterile PCR tubes. All preparations were executed under ice conditions. The antibiotics under study, including Ery as a positive control where then added to the reaction master-mix, with final concentration ranging from $5-100 \mu \mathrm{M}$. Ethanol (EtOH) was used as a negative control for the experiment, with its final concentration adjusted to $1 \%$ in all reactions. The samples where then incubated at room temperature for $\sim 2-3$ minutes. The samples were then placed back on ice. The Fluc mRNA template $(0.5 \mu \mathrm{L})$ was added last in the reaction mixture. Using a microplate reader (VICTOR X5 Light Plate Reader, PerkinElmer, USA), chemiluminescence profiles were detected and scored as counts per second (CPS). Reactions were performed in replicates.

\subsubsection{MTT cytotoxicity assay (Mosmann)}

MCF7, VA13, A549 and HEK293T cell lines were maintained in DMEM/F-12 (Thermo Fisher Scientific, USA) culture medium containing 10\% fetal bovine serum (Thermo Fisher Scientific, USA), $50 \mathrm{u} / \mathrm{ml}$ penicillin and $0.05 \mathrm{mg} / \mathrm{ml}$ streptomycin at $37^{\circ} \mathrm{C}$ (Thermo Fisher Scientific, USA) in 5\% $\mathrm{CO}_{2}$. Cell cultures were tested with MycoReport kit \#MR001 (Evrogen LLC, Russia) for the absence of mycoplasma annualy. Human breast cancer cell line MCF7, and human lung adenocarcinoma cell line A549 were kindly provided by Dr. S. Dmitriev, immortalized human fibroblasts cell line VA13 were kindly provided by Dr. M. Rubtsova, human embryonic kidney HEK293T cell line were kindly provided by Dr. E. Knyazhanskaya. Cell lines 
A549, MCF7, VA13 and HEK293T were verified by STR genotyping (COrDIS Plus assay, Gordis LLC, Russia).

The cytotoxicity of tested substances was tested using the MTT (3-(4,5-dimethylthiazol-2yl)2,5-diphenyl tetrazolium bromide) assay [19] with some modifications. 2500 cells per well for MCF7, HEK293T and A549 cell lines, or 4000 cells per well for VA-13 cell line were plated out in $135 \mu \mathrm{L}$ of DMEM-F12 media (Gibco, USA) in 96-well plate and incubated in the 5\% CO2 incubator for first $16 \mathrm{~h}$ without treating. Then $15 \mu \mathrm{L}$ of media-DMSO solutions of tested substances to the cells (final DMSO concentrations in the media were $1 \%$ or less) and treated cells $72 \mathrm{~h}$ with $50 \mathrm{nM}-100 \mu \mathrm{M}$ (eight dilutions) of our substances (triplicate each), with doxorubicin as a control. The MTT reagent (Paneco LLC, Russia) then was added to cells up to final concentration of $0.5 \mathrm{~g} / \mathrm{L}$ (10X stock solution in PBS was used) and incubated for $2 \mathrm{~h}$ at $37^{\circ} \mathrm{C}$ in the incubator, under an atmosphere of 5\% CO2. The MTT solution was then discarded and $140 \mu \mathrm{L}$ of DMSO (PharmaMed LLC, Russia) was added. The plates were swayed on a shaker ( $80 \mathrm{rpm}$ ) to dissolve the formazan. The absorbance was measured using a microplate reader (VICTOR X5 Light Plate Reader, PerkinElmer, USA) at a wavelength of $565 \mathrm{~nm}$ (in order to measure formazan concentration). The results were used to construct a dose-response graph and to estimate IC50 values (GraphPad Software, Inc., San Diego, CA).

\section{Results and discussion}

\subsection{6-OH-Tetracenomycin $\mathrm{X}$ isolation and structure elucidation}

Culture broth of previously studied Amycolatopsis sp. A23 strain - the producer of TcmX was found to contain minor compound with close retention time (Figure 2). 


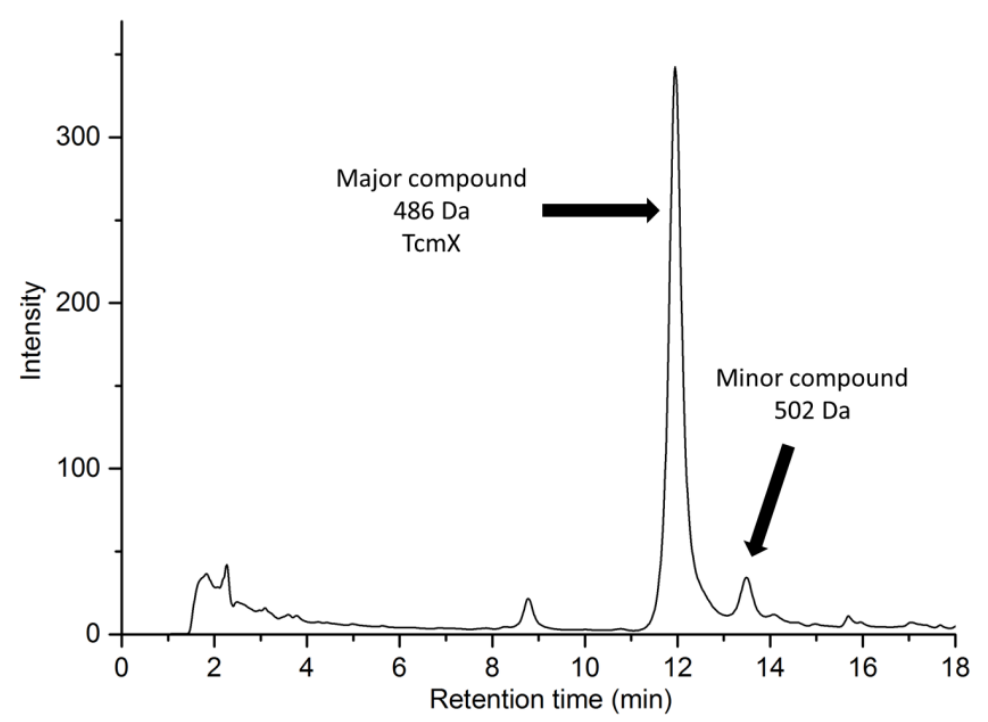

Figure 2. A typical analytical HPLC profile of Amycolatopsis sp. A23 extract active fraction, eluted with $50 \%$ acetonitrile.

The minor compound was purified with preparative HPLC (Figure S1). Structure of the isolated compound has been determined using the MS and NMR data. The mass of the compound (502 Da) was larger than the mass of tetracenomycin (TcmX) by 16 Daltons, which suggested the addition of one oxygen atom to the original antibiotic molecule. The position of the new hydroxyl group formed by oxidative hydroxylation was unambiguously determined using the NMR data.

In comparison with TcmX, in the ${ }^{1} \mathrm{H}$ spectrum of the novel congener (Figure S2), signal H6 disappears and one additional $\mathrm{OH}$ signal appears in the low field of the spectrum (12.25 ppm). New OH signal has strong NOE to the signal of $\mathrm{H} 7$ (Figure S3), suggesting that this is OH group in position 6. This assumption was rigorously proved after the making of ${ }^{1} \mathrm{H}$ and ${ }^{13} \mathrm{C}$ signal assignments by analyzing the $2 \mathrm{D}{ }^{13} \mathrm{C}-{ }^{1} \mathrm{H}$ HSQC and ${ }^{13} \mathrm{C}-{ }^{1} \mathrm{H}$ HMBC experiments (Figure S4) and 1D ${ }^{13} \mathrm{C}$ spectrum (Figure S5), and then comparing the experimentally measured chemical shifts with those calculated using the quantum mechanics (Table S6). Figure 2A summarizes all connections between the ${ }^{1} \mathrm{H}$ and ${ }^{13} \mathrm{C}$ nuclei observed in HMBC and ROESY spectra. It should be noted that far from all ${ }^{13} \mathrm{C}$ signals could be detected in $\mathrm{HMBC}$ spectrum, since most ${ }^{13} \mathrm{C}$ nuclei have very small or zero constants of spin-spin interaction with ${ }^{1} \mathrm{H}$ nuclei. However, all ${ }^{13} \mathrm{C}$ signals are observed in the $1 \mathrm{D}^{13} \mathrm{C}$ spectrum (Figure S5). 

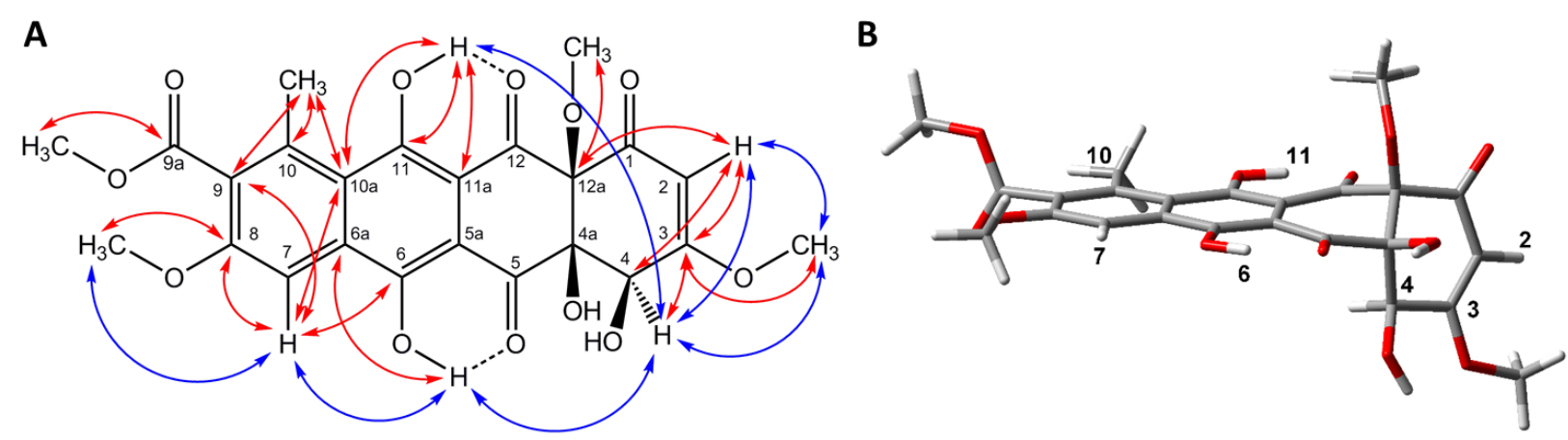

Figure 3. A) Molecular structure of 6-OH-TcmX with numerations of atoms and correlations between the ${ }^{1} \mathrm{H}$ and ${ }^{13} \mathrm{C}$ nuclei, which can be observed in ${ }^{13} \mathrm{C}-{ }^{1} \mathrm{H}$ HMBC spectrum (red arrows) and ${ }^{1} \mathrm{H}-{ }^{1} \mathrm{H}$ ROESY spectrum (blue arrows); B) Three dimensional structure of 6$\mathrm{OH}-\mathrm{TcmX}$ obtained after DFT optimization using the B3LYP functional, 6-311++G(2d,2p) basis set and the Polarizable Continuum Model of chloroform solvent. Shown are numerations of selected atoms.

The experimentally measured values of chemical shifts show excellent agreement (Pearson coefficient is 0.999899 ) with the values that were calculated quantum-mechanically for the optimized structure of 6-OH-TcmX (Figure 3B). The structure shown in Figure 3B explains, in particular, the weak NOEs between the $\mathrm{H} 4$ and both hydroxyl protons $\mathrm{OH} 6$ and $\mathrm{OH} 11$ observed in ROESY spectrum (Figure S3): distance from $\mathrm{H} 4$ to $\mathrm{OH} 6$ and $\mathrm{OH} 11$ is 4.5 and $4.0 \AA$ respectively.

Hydroxylation in the position 6 is rare in tetracene-type secondary metabolites: only three natural compounds, 6-OH-tetracenomycin C [20,21], elloramycin F [22], and F1T1 [23] (Figure 4), were each reported once in the literature in 1995, 1986, and 2007, respectively, accompanied with a scant data. 


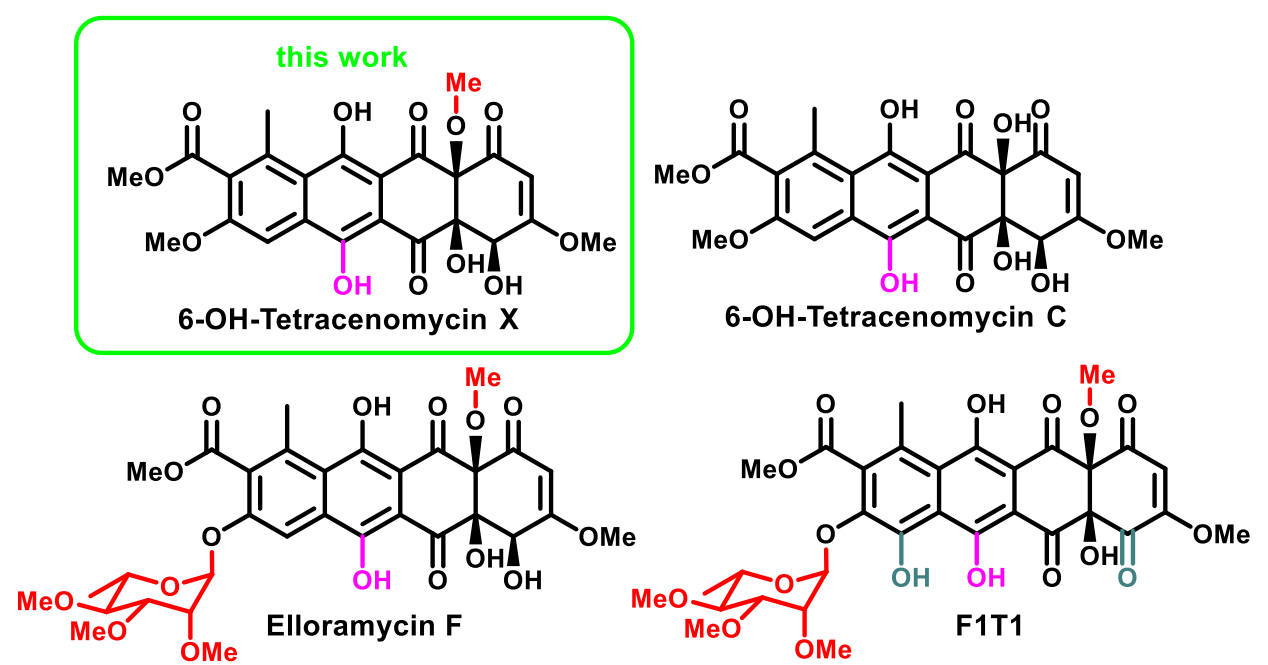

Figure 4. Structures of 6-hydroxylated tetracene-type secondary metabolites.

The biosynthetic origin of natural 6-hydroxylated tetracene-type compounds is not quite clear. In case of 6-OH-tetracenomycin $\mathrm{C}$, the hydroxylation was a result of the combination of the tetracenomycin and urdamycin biosynthetic gene clusters (BGCs) in one producing strain. It was convincingly showed, that 6-hydroxylation is catalyzed by UrdE oxygenase, involved into C-12 and $\mathrm{C} 12 \mathrm{~b}$ oxidation of urdamycin [20]. Surprisingly, neither elloramycin BGC (MiBIG BGC0000219), nor tetracenomycin BGC (Amycolatopsis sp. A23) contain proteins, homologous to UrdE. Complete genome sequence analysis of the Amycolatopsis sp. A23 revealed a number of proteins, moderately similar to UrdE (protein identity $\sim 40 \%$ ). Therefore, the protein involved in the biosynthesis of 6-OH-TcmX is most likely encoded outside the core Tcm BGC. Potentially, differences in the regulation of this gene could be a plausible cause for the low hydroxylated product yield obtained.

\subsection{Spectral characteristics of tetracenomycins}

Previously tetracenomycins attracted relatively low attention, comparing with most common aromatic polyketides. To a large extent, only qualitative UV data was available. Therefore, we decided to study and compare UV absorption and fluorescence of TcmX and 6-OH-TcmX.

TcmX exhibited similar absorbance maxima in methanol and ethanol, and slight bathochromic shifts in DMSO and water, along with some decrease in absorbance (Figure 5A, C). Decrease of extinction coefficients in water may cause difficulties in quantification of TcmX in 
spirits, due to variations in water contents in the used solvents. Therefore, $\mathrm{MeCN}$ is a more suitable solvent for TcmX quantification. DMSO might be used as an alternative in case of poorly soluble drug conjugates quantification.

We also studied pH-dependence of the TcmX water solution (Figure 5B). All the differences, observed in high $\mathrm{pH}$ region were found to be fully reversible. The pattern of $\mathrm{pH}$ dependence is similar to that observed for naphtol derivatives due to $\mathrm{OH}$-proton acidity $(\mathrm{pKa}(\mathrm{OH}) \sim 9.5)$, leading to the formation of naphtolate anion at $\mathrm{pH}>9$ [24]. The reversible nature of TcmX UV absorbance changes suggests the stability of the compound under basic conditions.
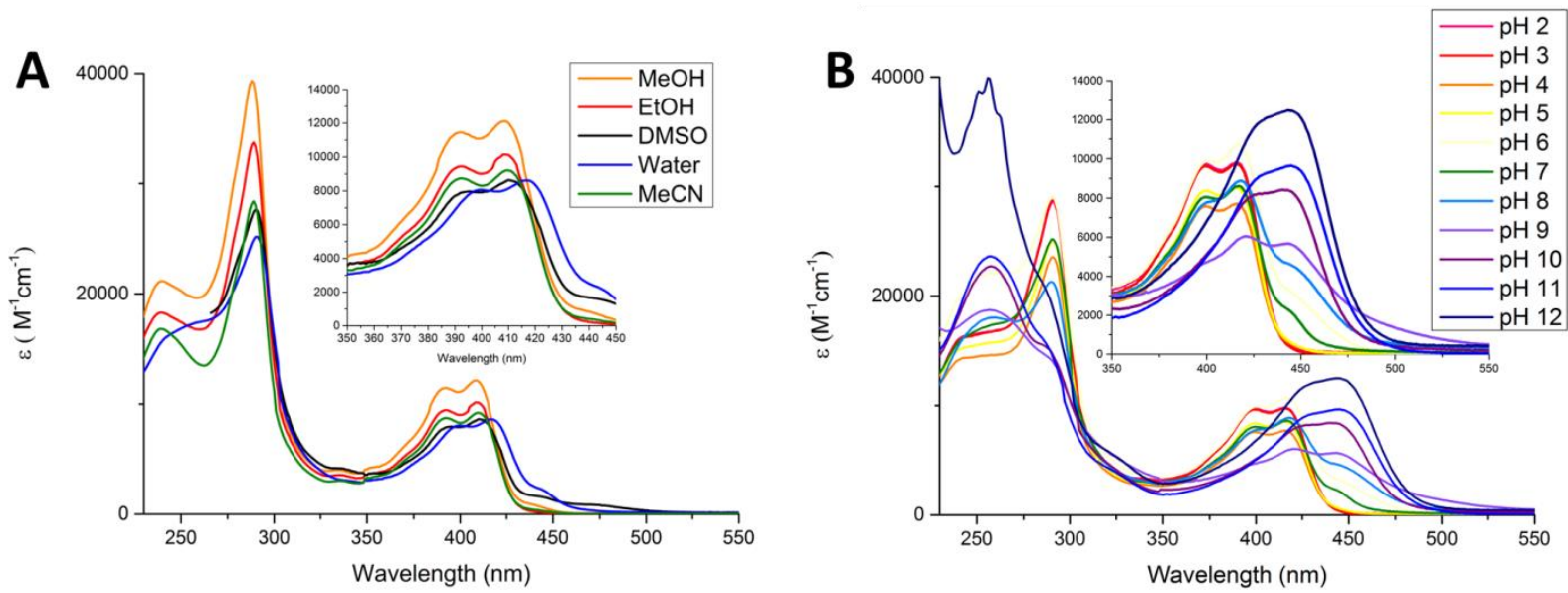

\begin{tabular}{c|cccc} 
C Solvent & \multicolumn{4}{|c}{ UV/Vis $\lambda_{\text {max }}, \mathrm{nm}\left(\varepsilon, \mathrm{M}^{-1} \mathrm{~cm}^{-1}\right)$} \\
\hline MeOH & $240(4.33)$ & $288(4.59)$ & $392(4.06)$ & $409(4.08)$ \\
EtOH & $239(4.26)$ & $289(4.53)$ & $392(3.98)$ & $408(4.01)$ \\
DMSO & below cutoff & $290(4.44)$ & $395(3.90)$ & $410(3.94)$ \\
Water & - & $291(4.40)$ & $399(3.91)$ & $417(3.94)$ \\
MeCN & $239(4.23)$ & $289(4.45)$ & $392(3.94)$ & $410(3.96)$
\end{tabular}

Figure 5. A) UV-Vis spectra of TcmX in various solvents; B) $\mathrm{pH}$ dependence of TcmX $\mathrm{UV}$-Vis absorption; $\mathbf{C}$ ) the exact values of $\lambda_{\max }$ and extinction coefficients in various solvents for TcmX.

6-Hydroxylated tetracenomycin $\mathrm{X}(6-\mathrm{OH}-\mathrm{TcmX})$ showed considerable decrease in absorbance, both in UV and visible range, along with bathochromic shift of bands in visible area (Figure 6A). However, the attenuation coefficients of 6-OH-TcmX exhibited lower solvent dependence (Figure 6C). The pronounced long-wavelength band ( $\left.\lambda_{\max } 467 \mathrm{~nm}\right)$ that appeared in DMSO could be attributed to J-aggregate [25] arising from intermolecular hydrogen bonding. 

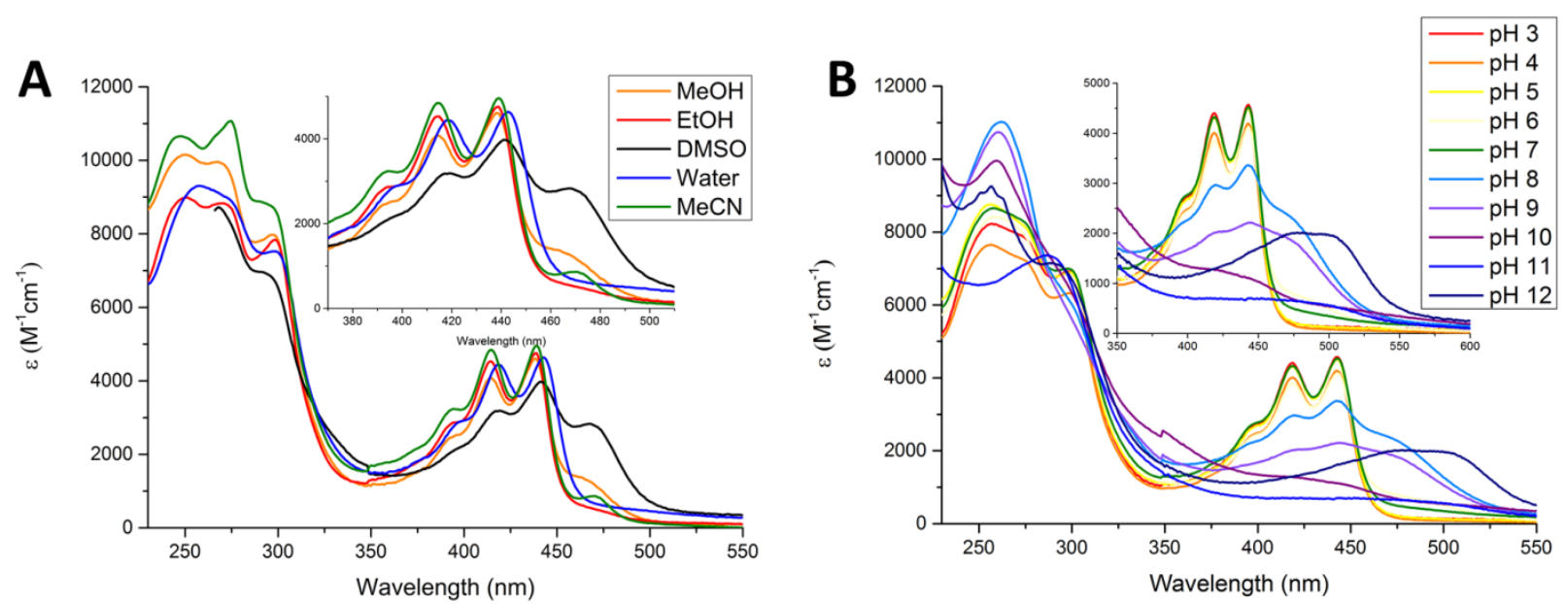

\begin{tabular}{c|cccccc} 
C Solvent & \multicolumn{5}{|c}{ UV/Vis $\lambda_{\max }, \mathrm{nm}\left(\varepsilon, \mathrm{M}^{-1} \mathrm{~cm}^{-1}\right)$} \\
\hline MeOH & $251(3.95)$ & $271(3.94)$ & $298(3.89)$ & $414(3.66)$ & $439(3.68)$ & \\
EtOH & $250(4.00)$ & $268(3.99)$ & $297(3.90)$ & $414(3.61)$ & $438(3.66)$ & \\
DMSO & below cutoff & $268(3.92)$ & $291(3.84)$ & $419(3.50)$ & $441(3.60)$ & $468(3.39)$ \\
Water & - & $258(3.97)$ & $297(3.87)$ & $418(3.65)$ & $443(3.67)$ & \\
MeCN & $248(4.03)$ & $275(4.04)$ & & $415(3.69)$ & $439(3.70)$ &
\end{tabular}

Figure 6. A) UV-Vis spectra of 6-OH-TcmX in various solvents; B) $\mathrm{pH}$ dependence of 6$\mathrm{OH}-\mathrm{TcmX} \mathrm{UV}-\mathrm{V}$ is absorption; $\mathbf{C}$ ) the exact values of $\lambda_{\max }$ and extinction coefficients in various solvents for 6-OH-TcmX.

Despite the lower absorbance of 6-OH-TcmX, visually its solutions have deeper yellow color relative to TcmX, due to longer wavelengths maxima in visible area (Figure 7). For hydroxylated congener we also observed $\mathrm{pH}$-dependent changes in UV-Vis spectrum (Figure 6B), presumably due to ionization of phenolate $\mathrm{OH}$-groups. The profound curve change at $\mathrm{pH} 11-12$, accompanied with a dramatic $\lambda_{\max }$ shift, is putatively caused by formation of di-anionic form of 6-OH-TcmX. The absence of a characteristic long-wavelength bond doubling, caused by hydrogen bond formation in the protonated form of the molecule, corroborates this assumption. A similar behavior was previously reported for dihydroxyanthraquinones [26]. 


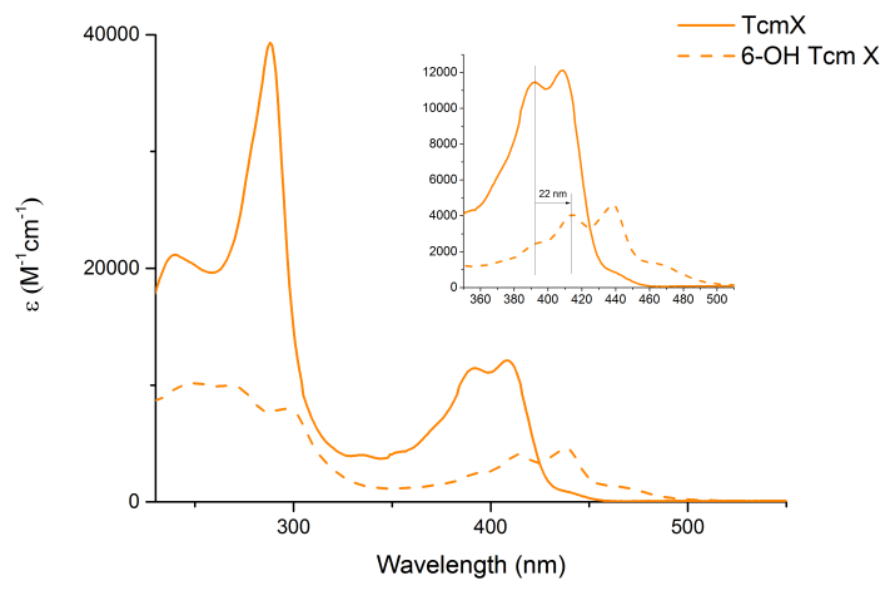

Figure 7. Comparison of the UV-Vis spectra profiles for 6-OH-TcmX and TcmX in $\mathrm{MeOH}$.

Previously tetracenomycins were visualized on TLC plates by fluorescence under UV light $(366 \mathrm{~nm})[27,28]$, however, no fluorescence and excitation spectra was provided. Therefore, we decided to investigate emission properties of the isolated tetracenomycins (Figure 8). Both compounds exhibited weak fluorescence, with $\mathrm{TcmX}$ showing practically no dependence on solvent polarity with emission $\lambda_{\max } 449.5,449$ and $452.5 \mathrm{~nm}$ in $\mathrm{MeOH}$, EtOH and DMSO respectively. In the case for 6-OH-TcmX, we observed slightly red-shifted maxima at 450.5, 451.5 and $457 \mathrm{~nm}$ in $\mathrm{MeOH}$, EtOH and DMSO respectively, showing more pronounced solvatochromic effect.
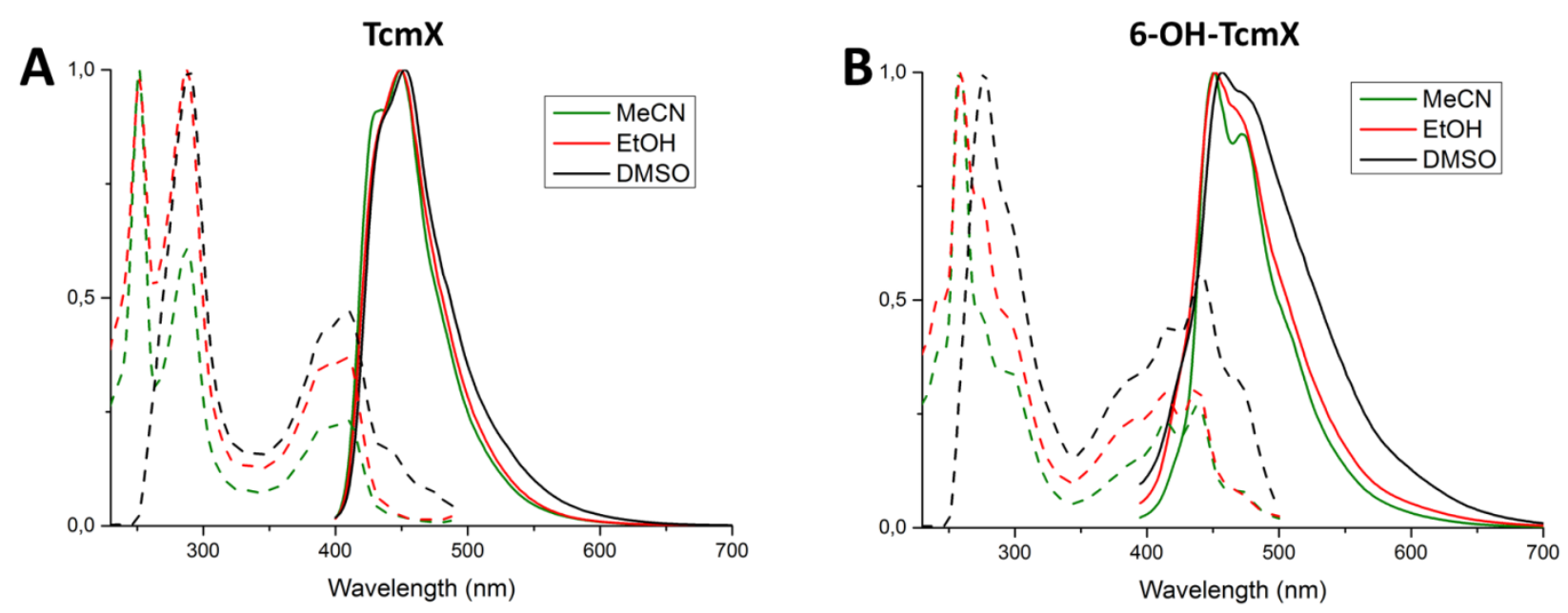

Figure 8. A) Normalized excitation (dashed line) and fluorescence (solid line) of TcmX; for emission $\mathrm{c}-5 \cdot 10^{-6} \mathrm{M}, \lambda_{\mathrm{em}}-380 \mathrm{~nm}$; for exitation $\mathrm{c}-2.5 \cdot 10^{-6} \mathrm{M}, \lambda_{\mathrm{ex}}-500 \mathrm{~nm}$. B) 
Normalized excitation (dashed line) and fluorescence (solid line) of 6-OH-TcmX; for emission c $-10^{-5} \mathrm{M} \lambda_{\mathrm{em}}-375 \mathrm{~nm}$; for exitation $\mathrm{c}-5 \cdot 10^{-6} \mathrm{M}, \lambda_{\mathrm{ex}}-515 \mathrm{~nm}$.

\subsection{Biological activity of tetracenomycins}

Data on biological activity of the previously described 6-hydroxylated congeners of tetracenomycins is scarce. Elloramycin F, containing 6-OH moiety, was structurally characterized along with a number of other elloramycins [22]. Surprisingly, unlike the other isolated compounds, no information on antimicrobial properties for elloramycin $\mathrm{F}$ was reported, whereas all other elloramycins (A-E) exhibited pronounced antibacterial activity. As for the second structurally related compound - 6-OH-TcmC - the study focused mainly on the biosynthetic context, with no particular report on biological activity [20,21].

We measured antimicrobial activity of the isolated 6-OH-TcmX, along with cytotoxic properties (Figure 7). Surprisingly, in comparison with non-hydroxylated congener, 6-OH-TcmX exhibited significantly lower activity on both bacterial (Figure 7A) and mammalian cells (Figure 7B). Nonetheless, the ability to inhibit protein synthesis in vitro was found to be the same for TcmX and 6-OH-TcmX (Figure7C). These findings allow us to deduce that, the decrease in activity on hydroxylated compound is not concerned with lower target affinity. In addition, the previously deduced structure of TcmX in complex with ribosome corroborates with this notion, as hydroxylation in position 6 does not interfere the key target interaction sites [11]. 


\begin{tabular}{|c|c|c|}
\hline \multirow{2}{*}{ A } & \multicolumn{2}{|c|}{$\begin{array}{l}\text { Cytotoxicity } \\
\qquad \mathrm{IC}_{50}(\mu \mathrm{M})\end{array}$} \\
\hline & $\operatorname{Tcm} X$ & 6-OH-TcmX \\
\hline Va13 & $0.77 \pm 0.05$ & $9.7 \pm 0.74$ \\
\hline Hek293t & $0.98 \pm 0.06$ & $18.6 \pm 1.6$ \\
\hline A549 & $1.28 \pm 0.11$ & $13.38 \pm 0.92$ \\
\hline Mcf7 & $2.69 \pm 0.23$ & $24.96 \pm 2.41$ \\
\hline \multirow[t]{3}{*}{ B } & \multicolumn{2}{|c|}{ Antibacterial activity } \\
\hline & \multicolumn{2}{|c|}{$\operatorname{MIC}(\mu \mathrm{g} / \mathrm{mL})$} \\
\hline & TcmX & 6-OH-TcmX \\
\hline$\Delta$ tolC E.coli & 2 & 16 \\
\hline \multirow[t]{3}{*}{ C } & \multicolumn{2}{|c|}{ In vitro translation inhibition } \\
\hline & \multicolumn{2}{|c|}{ Normalized CPS } \\
\hline & TcmX & 6-OH-TcmX \\
\hline $10 \mu \mathrm{M}$ & $0.04 \pm 0.01$ & $0.03 \pm 0.01$ \\
\hline $100 \mu \mathrm{M}$ & $0.001 \pm 0.0005$ & $0.001 \pm 0.0005$ \\
\hline
\end{tabular}

Figure 7. Comparison of biological properties for TcmX and 6-OH-TcmX. A) Cytotoxicyty (MTT test) for the several cell lines. B) MIC for the test microorganism. C) The normilized Fluc luminescence CPS for in vitro translation inhibition experiment (1 corresponds to negative control), tested for 2 concentrations of both compounds.

Rational engineering of type II PKSs for large scale production and structural diversification draws significant attention due to their attractive biological activities and pharmacological properties [6]. Our findings from structure-activity relationship in tetracenomycins' structural family indicates that a 6-hydroxylation leads to decrease in antibiotic properties, with retention of binding ability. Furthermore, this might be considered a plausible modification site in complex diversification strategies, with potency to overcome penetration disadvantages in 6-hydroxylated molecules.

\section{Conclusion}

In this work, we isolated a novel member of tetracenomycins' structural family and explored spectral characteristics, along with the structure-activity relationship characterization for these aromatic polyketides. Taking into account their recently discovered original binding site in large ribosomal subunit, tetracenomycins became attractive basis for structural diversification and 
semisynthetic drug development. Our findings indicate, that 6-hydroxylation leads to significant alterations in $\mathrm{TcmX}$ chromophore and decrease of both antibacterial activity and cytotoxicity. Nonetheless, the ability of 6-OH-TcmX to inhibit protein synthesis is comparable with that of TcmX, thus suggesting similar binding with molecular target.

\section{Acknowledgements}

The research was supported in part by the Russian Science Foundation project No 20-1500361 to V.A.A and V.A.K. (purification and characterization of compounds), Russian Foundation of Basic Research 20-54-76002 to I.A.O. (in vitro translation), Russian Science Foundation project No 19-14-00115 to V.I.P (NMR studies), Interdisciplinary Scientific and Educational School of Moscow University «Molecular Technologies of the Living Systems and Synthetic Biology», President grant MD 2626.2021.1.4 to I.A.O. (bacteria inhibition assays) and in part funded by Sirius University (Producer cultivation). The authors are grateful to the Moscow State University (Russia) for the opportunity to use the NMR facilities, Oleg Saveliev for the expert technical assistance in the NMR measurements and Dr. V.A. Chertkov (MSU, Moscow) for providing computing resources to carry out the DFT calculations.

\section{References}

[1] M. Richardson, C. Khosla, Structure, function, and engineering of bacterial aromatic polyketide synthases, in: Comprehensive Natural Products Chemistry, Elsevier, 1999: pp. 473-494. https://doi.org/10.1016/B978-0-08-091283-7.00019-9.

[2] C. Hertweck, A. Luzhetskyy, Y. Rebets, A. Bechthold, Type II polyketide synthases: gaining a deeper insight into enzymatic teamwork, Nat. Prod. Rep. 24 (2007) 162-190. https://doi.org/10.1039/B507395M.

[3] J. Rohr, C. Hertweck, Type II PKS, in: Comprehensive Natural Products II, Elsevier, 2010: pp. 227-303. https://doi.org/10.1016/B978-008045382-8.00703-6.

[4] T.P. Korman, B. Ames, S.-C. (Sheryl) Tsai, Structural enzymology of polyketide synthase: the structure-sequence-function correlation, in: Comprehensive Natural Products II, Elsevier, 2010: pp. 305-345. https://doi.org/10.1016/B978-008045382-8.00020-4.

[5] Y. Hu, Q.-Y. Nie, H.-X. Pan, G.-L. Tang, Bacterial type II polyketide synthases, in: Comprehensive Natural Products III, Elsevier, 2020: pp. 198-249. https://doi.org/10.1016/B978-0-12-409547-2.14626-8.

[6] J. Wang, R. Zhang, X. Chen, X. Sun, Y. Yan, X. Shen, Q. Yuan, Biosynthesis of aromatic polyketides in microorganisms using type II polyketide synthases, Microb Cell Fact. 19 (2020) 110. https://doi.org/10.1186/s12934-020-01367-4. 
[7] J. Marinello, M. Delcuratolo, G. Capranico, Anthracyclines as topoisomerase II poisons: from early studies to new perspectives, Int. J. Mol. Sci. 19 (2018) 3480. https://doi.org/10.3390/ijms19113480.

[8] D.N. Wilson, Ribosome-targeting antibiotics and mechanisms of bacterial resistance, Nat. Rev. Microbiol. 12 (2014) 35-48. https://doi.org/10.1038/nrmicro3155.

[9] M.K. Kharel, P. Pahari, M.D. Shepherd, N. Tibrewal, S.E. Nybo, K.A. Shaaban, J. Rohr, Angucyclines: biosynthesis, mode-of-action, new natural products, and synthesis, Nat. Prod. Rep. 29 (2012) 264-325. https://doi.org/10.1039/C1NP00068C.

[10] A.A. Mikhaylov, V.A. Ikonnikova, P.N. Solyev, Disclosing biosynthetic connections and functions of atypical angucyclinones with a fragmented C-ring, Nat. Prod. Rep. (2021) 10.1039.D0NP00082E. https://doi.org/10.1039/D0NP00082E.

[11] I.A. Osterman, M. Wieland, T.P. Maviza, K.A. Lashkevich, D.A. Lukianov, E.S. Komarova, Y.V. Zakalyukina, R. Buschauer, D.I. Shiriaev, S.A. Leyn, J.E. Zlamal, M.V. Biryukov, D.A. Skvortsov, V.N. Tashlitsky, V.I. Polshakov, J. Cheng, Y.S. Polikanov, A.A. Bogdanov, A.L. Osterman, S.E. Dmitriev, R. Beckmann, O.A. Dontsova, D.N. Wilson, P.V. Sergiev, Tetracenomycin $\mathrm{X}$ inhibits translation by binding within the ribosomal exit tunnel, Nat. Chem. Biol. 16 (2020) 1071-1077. https://doi.org/10.1038/s41589-020-0578-X.

[12] Y.V. Zakalyukina, M.V. Birykov, D.A. Lukianov, D.I. Shiriaev, E.S. Komarova, D.A. Skvortsov, Y. Kostyukevich, V.N. Tashlitsky, V.I. Polshakov, E. Nikolaev, P.V. Sergiev, I.A. Osterman, Nybomycin-producing Streptomyces isolated from carpenter ant Camponotus vagus, Biochimie. 160 (2019) 93-99. https://doi.org/10.1016/j.biochi.2019.02.010.

[13] D.S. Wishart, C.G. Bigam, J. Yao, F. Abildgaard, H.J. Dyson, E. Oldfield, J.L. Markley, B.D. Sykes, ${ }^{1} \mathrm{H},{ }^{13} \mathrm{C}$ and ${ }^{15} \mathrm{~N}$ chemical shift referencing in biomolecular NMR, J Biomol NMR. 6 (1995) 135-140. https://doi.org/10.1007/BF00211777.

[14] F. Delaglio, S. Grzesiek, G.W. Vuister, G. Zhu, J. Pfeifer, A. Bax, NMRPipe: a multidimensional spectral processing system based on UNIX pipes, J. Biomol. NMR. 6 (1995) 277-293. https://doi.org/10.1007/BF00197809.

[15] W. Lee, M. Tonelli, J.L. Markley, NMRFAM-SPARKY: enhanced software for biomolecular NMR spectroscopy, Bioinformatics. $31 \quad$ (2015) 1325-1327. https://doi.org/10.1093/bioinformatics/btu830.

[16] M. J. Frisch, G. W. Trucks, H. B. Schlegel, G. E. Scuseria, M. A. Robb, J. R. Cheeseman, G. Scalmani, V. Barone, B. Mennucci, G. A. Petersson, H. Nakatsuji, M. Caricato, X. Li, H. P. Hratchian, A. F. Izmaylov, J. Bloino, G. Zheng, J. L. Sonnenberg, M. Hada, M. Ehara, K. Toyota, R. Fukuda, J. Hasegawa, M. Ishida, T. Nakajima, Y. Honda, O. Kitao, H. Nakai, T. Vreven, J. A. Montgomery, Jr., J. E. Peralta, F. Ogliaro, M. Bearpark, J. J. Heyd, E. Brothers, K. N. Kudin, V. N. Staroverov, R. Kobayashi, J. Normand, K. Raghavachari, A. Rendell, J. C. Burant, S. S. Iyengar, J. Tomasi, M. Cossi, N. Rega, J. M. Millam, M. Klene, J. E. Knox, J. B. Cross, V. Bakken, C. Adamo, J. Jaramillo, R. Gomperts, R. E. Stratmann, O. Yazyev, A. J. Austin, R. Cammi, C. Pomelli, J. W. Ochterski, R. L. Martin, K. Morokuma, V. G. Zakrzewski, G. A. Voth, P. Salvador, J. J. Dannenberg, S. Dapprich, A. D. Daniels, Ö. Farkas, J. B. Foresman, J. V. Ortiz, J. Cioslowski, and D. J. Fox, Gaussian 09 (Gaussian, Inc., Wallingford CT, 2009)., (n.d.).

[17] C. Adamo, V. Barone, Exchange functionals with improved long-range behavior and adiabatic connection methods without adjustable parameters: The $\mathrm{mPW}$ and $\mathrm{mPW} 1 \mathrm{PW}$ models, J. Chem. Phys. 108 (1998) 664-675. https://doi.org/10.1063/1.475428.

[18] M.W. Lodewyk, M.R. Siebert, D.J. Tantillo, Computational prediction of ${ }^{1} \mathrm{H}$ and ${ }^{13} \mathrm{C}$ chemical shifts: a useful tool for natural product, mechanistic, and synthetic organic chemistry, Chem. Rev. 112 (2012) 1839-1862. https://doi.org/10.1021/cr200106v.

[19] T. Mosmann, Rapid colorimetric assay for cellular growth and survival: Application to proliferation and cytotoxicity assays, J. Immunol. Methods. 65 (1983) 55-63. https://doi.org/10.1016/0022-1759(83)90303-4. 
[20] H. Decker, S. Haag, Cloning and characterization of a polyketide synthase gene from Streptomyces fradiae Tü2717, which carries the genes for biosynthesis of the angucycline antibiotic urdamycin A and a gene probably involved in its oxygenation, J. Bacteriol. 177 (1995) 6126-6136. https://doi.org/10.1128/jb.177.21.6126-6136.1995.

[21] H. Decker, S. Haag, G. Udvarnoki, J. Rohr, Novel genetically engineered tetracenomycins, Angew. Chem. Int. Ed. 34 (1995) 1107-1110. https://doi.org/10.1002/anie.199511071.

[22] H.-P. Fiedler, J. Rohr, A. Zeeck, Elloramycins B, C, D, E and F: Minor congeners of the elloramycin producer Streptomyces olivaceus., J. Antibiot. 39 (1986) 856-859. https://doi.org/10.7164/antibiotics.39.856.

[23] B.H. Nga, H.M. Tan, Polyketides and uses thereof, 2007. https://patentscope.wipo.int/search/en/detail.jsf?docId=WO2007106041 (accessed July 15, 2021).

[24] M.S. Groves, K.J. Nelson, R.C. Nelson, K. Takematsu, pH switch for OH-photoacidity in 5-amino-2-naphthol and 8-amino-2-naphthol, Phys. Chem. Chem. Phys. 20 (2018) 2132521333. https://doi.org/10.1039/C8CP03984D.

[25] N.J. Hestand, F.C. Spano, Expanded theory of H- and J-molecular aggregates: the effects of vibronic coupling and intermolecular charge transfer, Chem. Rev. 118 (2018) 7069-7163. https://doi.org/10.1021/acs.chemrev.7b00581.

[26] Z. Machatová, Z. Barbieriková, P. Poliak, V. Jančovičová, V. Lukeš, V. Brezová, Study of natural anthraquinone colorants by EPR and UV/vis spectroscopy, Dyes Pigm. 132 (2016) 79 93. https://doi.org/10.1016/j.dyepig.2016.04.046.

[27] G. Lazar, H. Zähner, S. Breiding, M. Damberg, A. Zeeck, 3-Demethoxy-3-ethoxytetracenomycin C., J. Antibiot. $34 \quad$ (1981) 1067-1068. https://doi.org/10.7164/antibiotics.34.1067.

[28] B. Shen, C.R. Hutchinson, Triple hydroxylation of tetracenomycin A2 to tetracenomycin $\mathrm{C}$ in Streptomyces glaucescens. Overexpression of the tcmG gene in Streptomyces lividans and characterization of the tetracenomycin A2 oxygenase., J. Biol. Chem. 269 (1994) 3072630733. https://doi.org/10.1016/S0021-9258(18)43874-4. 